\title{
The Impact of Mutual Health Insurance Scheme on Access and Quality of Health Care in Northern Ghana: The Case of Kassena-Nankana East Scheme
}

\author{
Kennedy A. Alatinga \\ Lecturer, University for Development Studies, Department of Community Development, Ghana \\ P.O. Box 520, Wa Campus, Upper West Region, Ghana \\ Tel: 233-244-933-750Ｅ-mail: kalatinga@gmail.com \\ Nicholas Fielmua \\ Research Fellow, University for Development Studies \\ Centre for Continuing Education and Interdisciplinary Research (CCEIR) \\ P.O. Box 520, Wa Campus, Upper West Region, Ghana \\ Tel: 233-243-255-001Ｅ-mail: fielmua@yahoo.com
}

Received: June 20, 2011

Accepted: August 31, 2011

doi:10.5539/jsd.v4n5p125

\begin{abstract}
This study examines the Impact of Mutual Health Insurance on Access and Quality of Health Care for the Rural Poor in Northern Ghana. The practical interest in Mutual Health Insurance is occasioned by the fact that many developing countries including Ghana are exploring new and innovative ways of dealing with the difficult issues of health care financing and access to health care especially for the rural poor. Using household surveys and focus group discussions, the study establishes that Mutual Health Insurance improves the poor access to health care as the insured use nearly 3 times of health facilities more than the uninsured. The insured equally pay relatively lower out-of-pocket fees than the uninsured at the point of demanding health care. Households with higher incomes generally enrol in health insurance while the poorest segment of the community risk being excluded because they cannot afford the insurance premiums. It is recommended that since the flat rate nature of insurance premiums is what prevents majority of households from enrolling in health insurance, the premiums could be made more flexible for the rural poor.
\end{abstract}

Keywords: Mutual health Insurance, Access, Quality, Health, Northern, Ghana

\section{Background of the Study}

Health and social security are human rights and indispensable prerequisites for poverty reduction, economic growth and development. Consequently, there is the need for appropriate health financing mechanisms that will raise sufficient funds and create suitable financial incentives so that everyone especially the rural poor has access to affordable health care. Improving the rural poor's access to health care will enable them to contribute meaningfully towards the development agenda. In today's age of scientific and technological advancement, preventable diseases and illnesses still remain critical threats to the income earning capacity of the world's rural poor. Physical and financial barriers to accessing quality health care remain problems for the poor majority especially in developing countries.

It is estimated that 1.3 billion people in the world lack access to effective and affordable health care due to financial limitations or governments' inability to provide them with the necessary coverage (WHO, 2005). The poor are most often than not required to pay for the cost of health out-of pocket at the very moment they fall sick. Out-of-pocket payments mostly in the form of user fees describe all expenses that patients have to pay to a health care provider according to set tariffs and directly out of their own pockets (Lasser and Rademacher, 2006). These out-of-pocket payments exclude a lot of the poor from accessing health care because they cannot afford. These out-of-pocket payments or expenditures may even be catastrophic and can plunge families or individuals into perpetual impoverishment. Expenditures are termed 'catastrophic' if they exceed a certain fraction of household income say for example 40\% of household income (Wagstaff, 2008). Similarly, Preker and Carrin (2004) argue 
that financial constraints have been identified as one of the most important factors that excludes the poor from accessing health care in developing countries. They argue that despite the fact that 84 percent of the world's poor bear 93 percent of the global burden of disease, the poor benefit from only $11 \%$ of worldwide health expenditure. Consequently, sick low-income households in rural areas continue to use home remedies, traditional healers, and local providers who are often outside the formal health system because of the high cost of accessing health care at the formal health facilities. For instance, it is estimated that about $80 \%$ of African population are excluded from health care due to out-of-pocket payments (Bailey, 2004).

In Ghana, health financing was based on a "cash and carry" system in which patients had to directly pay out of their pockets for medical services immediately after receiving treatment. For instance, in 2005 out-of-pocket expenditure as a percentage of private expenditure on health in Ghana was $79.10 \%$ (WHO, 2005). The cash and carry system limited access to health care and reduced the use of health facilities especially by poor people and other disadvantaged groups. Studies show that due to the significant increase in user fees in 1989, there was a sharp decline in utilisation both at rural and urban clinics with the brunt falling on the former irrespective of their lower fees (Waddington and Enyimayew, 1989). The UNDP (2007) estimates that about 70 percent of the population of Ghana use alternative medicine which includes traditional health care while 30 percent rely on orthodox medical care. The report further posits that in terms of orthodox health care in Ghana, only $18.4 \%$ of the sick or injured consulted a health practitioner and a sizeable proportion of rural areas and northern Ghana generally are excluded due to the inability to pay. Due to the exclusionary nature of out-of-pocket payments and high of costs of treatment, the Ghanaian parliament in 2003 passed the National Health Insurance (NHI) Act, Act 650 promoting the establishment of Mutual Health Insurance Schemes in all parts of the country. The scheme gives prominence to Community/District Mutual Health Insurance Schemes as a key strategy for the extension of financial protection in health to the poor. Financial protection may be described as the protection for households or individuals against the financial consequences of illness and death, or at least from the financial consequences associated with the use of medical care (Wagstaff, 2008).

It is against this background that this paper seeks to examine the impact of these novel schemes on the beneficiaries in terms of financial protection against economic cost of illness and access to quality health care services. Despite the recent growth of scholarship on health care financing at the community level, there is still a dearth of systematic evidence in relation to the performance of these schemes in terms of their impact on protection against impoverishment. Much is yet to be discovered about their effectiveness in improving access to effective and quality health care; their role in sharing risks across population groups (Preker and Carrin, 2004). This research is an effort to contribute to bridging this knowledge gap.

\section{Theoretical and Conceptual Framework}

\subsection{How Pro-poor are Mutual Health Insurance Schemes (MHIS)}

Mutual Health Insurance (MHI) schemes are defined as "any non-profit health financing scheme. They cover any not-for-profit insurance scheme that is aimed primarily at the informal sector and formed on the basis of an ethic of mutual aid and the collective pooling of health risks, and in which the members participate in its management"(Musau, 1999, cited in Preker and Carrin, 2004:61). It is argued that one of the objectives of community-based health financing is giving the poor a voice in their own destinies and making them active participants in managing their resources (Preker and Carrin, 2004:14). MHI provides financial risk protection to low-income people who normally have irregular flow of incomes within rural and informal sectors and the participation of people in MHI is voluntary. MHI schemes are usually simple because premiums are not risk related. This means that premiums are flat rate for members irrespective of their health status; premiums are not based on individual risk. The flat rate nature of MHI makes it easier for the insurance scheme to calculate the premiums. Besides, formalities and procedures of MHI are normally simple because most people in the informal sector are unable to cope with procedural complexities; low-income households cannot afford to spend days away from work because they make their incomes on daily basis.

Similarly, MHI is usually affordable to members. Members generally pay low premiums reflecting their financial positions. The absolute level of premiums obviously makes a difference because when members perceive the scheme to be affordable; more members are attracted to join the scheme. In a bid to enhance affordability, MHI may even spread premium payments for its members over time to correspond with the household's cash flows. Again the confidence that, in a case of need, insurance will pay for the member also enhances trust and the individual willingness to pay (WTP). More so, members of MHI schemes have the advantage of proximity because the schemes are usually located near their client base, simply because the poor or members of the rural population have neither the means nor the latitude to travel from their place of residence 
to service centres. Given this background, MHI schemes seem to have a comparative advantage over other types of health insurance; Social Health Insurance (SHI) and Private Health Insurance (PHI) as far as the rural poor are concerned.

SHI is based on mandatory membership for specific legally defined population groups. This means that premiums or contributions in SHI are paid based on compulsory public pay-roll deductions and made by employers for a legally designated population. The fact that SHI is mandatory and income based, it has the potential of excluding the poorer populations in developing countries who are mostly informal sector workers and the unemployed. In fact, it is argued that there is a risk that the system may never move beyond the initial narrow base of formal sector workers and that, instead of "improving the situation of the poorer groups, it may increase inequities" (Conn and Walford, 1998 cited in Gottret and Schieber, 2006:88).

On the other hand, PHI thrives on the interplay of market forces: the laws of supply and demand determine the price of insurance products. PHI charges premiums based on the individual risk profiles. This leads to risk selection and cream skimming in the absence of regulations or incentives to counteract such practices. According to Zwifel (2007:24) "Cream skimming" refers to the practice of categorising individuals according to their risk profile. This means that private insurers make a conscious effort to attract favourable or "good" risks individuals in their pool leaving out "bad" risks individuals because of profit motives. Given that the poor mostly live in risky environments, they are more vulnerable to health risks (illness) and therefore stand a greater chance of being excluded from private health insurance because the premiums are risks related. It may also be argued that where there is no competition among PHI providers, PHI may charge very high premiums that majority of the rural people may be unable to afford. Besides, SHI and PHI are designed for specific populations; formal sector employees and the urban rich; thus the insurance needs of the rural population groups may not be met. Importantly, while PHI tends to exclude high-risk persons, MHI schemes generally strive to include them. MHI premiums are small and flat rate; not calculated based on individual risks, not profit oriented and are likely to include more people than PHI and SHI. From the comparative review above, Mutual Health Insurance Schemes appear to be more pro-poor in terms of health financing for the poor in rural areas. Studies by Jütting (2001:21) in rural Senegal establish that MHI can result in better access to health care for otherwise excluded people and members of MHI tend to have lower out-of-pocket expenditures than do non-members. Similar studies by (Jakab and Krishnan, 2004 cited in McIntyre, Gilson and Mutyambizi, 2005:29) in Mali found that mutual health insurance has improved utilisation of health services, even for the poor and helped households to better manage their health-care expenditures. They (MHI) reach "a large number of low-income populations who would otherwise have no financial protection against the cost of illness" (ibid). Further evidence suggests that MHI schemes are generally affordable and have the potential to reach larger sections of the poor population. For instance, to make medical insurance affordable in very poor communities in Peru, premiums of community based health insurance schemes are collected in the form of a portion of the annual potato harvest, which is then sold to finance health costs (Tabor, 2005). Based on the reasons stated above, we assert that Mutual Health Insurance is a better alternative to financing health care in rural settings compared with other forms of insurance.

Before moving onto the next section, it is appropriate to mention here that countries also try to alleviate the financial constraints of their citizenry by financing health services through the government budget (tax-funding) which "prepays" the costs of care (Gottret and Schieber, 2006:75). This option has the potential of extending universal coverage to the entire population; free access to everybody in the country. However, state-funded health systems have to compete annually with other equally important sectors within the economy for a share of the state budget. As a result, they may receive insufficient resources or the flow of resources (funds) may be unstable due to budget constraints on the part of the state. Consequently, resource constraints may make state-funded health systems inefficient; deliver poor quality service and unsustainable.

\subsection{Effectiveness of Mutual Health Insurance Schemes: Is there empirical evidence?}

Empirical studies suggest that community- financing schemes have unparalleled degree in reaching a wider section of rural populations achieved through community participation in utilisation of health services (Preker and Carrin, 2004). Thus, the effectiveness of MHI can be looked at from the demand and supply side of insurance. The demand for health insurance is a function of the premium which an insurer or insurance company charges its clients. Given that MHI schemes charge relatively lower premiums, people are attracted to demand more insurance against the backdrop that the insured can readily get treatment at the health facility when they fall sick and no longer have to search for credit or sell assets in other to access health care. Considering that the poor generally live in risky environments and the fact that people in rural areas rely mainly on their daily labour productivity and on assets such as livestock for income generation, the demand for health insurance by the rural poor would be high because they desire health insurance to guard them against the uncertainty of illness and 
having to pay for health expenses at the point of health service use. As a result, insurers design benefit packages that are in high demand by the poor because they are closer to their clients at the local level. Insurers then contract specific health providers to provide these specialised products or services of a certain standard or quality for their clients. Due to these contractual agreements the health providers try to provide required services to meet the specific needs of the clients, thereby strengthening the bargaining power of clients.

MHI is thus considered pro-poor as it strengthens the demand side and thereby helps the poor to articulate their own needs. However, the demand for health insurance at the rural community setting is influenced by the cultural environment, the norms and values in the society under consideration (Jütting, 2005). Thus if people see disease as a punishment for evil behaviour, they will not demand health insurance no matter how low insurance premiums are set. In some parts of rural Benin, for example, saving money for a disease is seen to be "wishing oneself the disease" (Tabor, 2005:29). Another study on the behaviour of Mafa women in Northern Cameroon with regards to illness indicates that for them, "illness is a disorder in their individual cosmos. In order to restore the balance, different biochemical, psychological and spiritual forces have to be tackled together. For the Mafa women the local healers are the privileged source for treatment as they offer a variety of services non-available at the local health post or the hospital: medicinal herbs, massage techniques and anti-witchcraft ceremonies"( Jütting, 2005:41). In these type of rural settings, the demand for health insurance risk being very low or even nonexistent.

On the supply side, adequate information is needed by MHI scheme to set the right prices. A key component in determining the price of an insurance policy is the expected likelihood that a covered loss will occur (tabor, 2005). Estimating this likelihood accurately is very important because unexpectedly high claims can quickly bankrupt an insurance plan. Data is needed on age, gender, geographic distribution, out-of-pocket health expenditures and utilisation data for major categories of health care. Unfortunately in poor communities, this information is often lacking so MHI restrict their benefit packages to services that are easier to price. Nevertheless, it is argued that MHI schemes have a great efficiency advantage over other forms of insurance in that they can draw on location-specific information to design benefit packages that meet the common priorities of their members.

\subsection{Hypotheses}

In line with the theoretical framework, the following hypotheses are formulated to be tested against empirical findings in the study area:

- MHI improves access to health care for insured households

- MHI members receive better quality health care than non-members

- Higher income households are more likely to enroll in health insurance than lower income households.

\section{Research Methodology}

\subsection{Research Strategy}

Mixed methods of research were used to elicit, collate and interpret information germane to the study. By mixed methods is meant the combination of both quantitative and qualitative strategies to collect and analyse data. The rationale for choosing this strategy is that the weakness of one will be complemented by the strengths of the other. Supporting this choice, it is argued that each approach has its own limitations or "imperfections", which can be compensated for by using an alternative method (Bryman, 2008).

\subsection{Sampling Procedure}

The target population was households of the insured and non-insured in the target area. Probability sampling which gives all the elements or units in the population equal chances of being selected was used. Specifically, cluster random sampling and stratified random sampling were used.

\subsubsection{Random Cluster Sampling.}

Given the dispersed nature of the rural communities in the study area, the communities have been further grouped into clusters by the Navrongo Demographic Surveillance System (NDSS). Two clusters or communities were randomly selected for the study. Given the geographical coverage of the District, random cluster sampling solved the problem of interviewers having to travel the length and breadth of these scattered communities looking for interviewees or respondents. 


\subsubsection{Stratified Random Sampling.}

Having selected the communities from which samples were drawn, the population of each community was categorised into two strata; the insured and the non-insured from which samples were drawn. To do this, a sampling frame containing a list of all the insured in the selected communities was obtained from the office of the health insurance scheme, while a list of all the inhabitants of the two selected communities was obtained from the NDSS. This list helped to establish the sampling frame of the non-insured from which the sample was drawn. In using stratified random sampling, both groups (insured and non-insured) were proportionately represented in the sample. In this regard, Bryman (2008:179) posits that stratification 'injects an extra increment of precision into probability sampling process, since a possible source sampling error is eliminated'.

\subsubsection{Sample Size}

A total of 100 interviews were conducted. Four Focus Group Discussions were held- two with each community. This choice of sample size was informed by the fact that 'decisions about sample size represent a compromise between the constraints of time and cost and the need for precision' (Bryman, 2008:179).

\subsection{Methods of Data Collection}

Household surveys were conducted with the insured and non-insured households. Interviews were also done with the staff of the MHI scheme. However, interviews with health service providers were not included. Mainly, semi structured interviews and Focus Group Discussions (FGDs) were used to collect data from the field. Semi structured questionnaire was used to elicit information from households or individuals with specific questions relating to access to health and quality of health care. The questionnaire was piloted to detect and correct deficiencies before the actual data collection began. The FGDs were used mainly but not exclusively to elicit information in relation to the quality of health care provided.

\subsection{Data Analysis}

A comparative analysis was done by comparing the two groups (insured and non-insured). The aim of doing a comparative analysis was to seek explanations for similarities and differences between the two groups. Data collected using the questionnaires were analysed using Microsoft STATA 10.0 and Windows SPSS 16.0. Specifically, two statistical methods were employed in the analysis: hypotheses testing and correlation analysis. The specific statistical methods used for the hypotheses testing include the t-test and the Mann-Whitney/Wilcoxon rank sum test. The t-test of two independent samples has been used to compare the means of the frequency of use of health facilities and the costs of treatment between the insured and uninsured. The t-test statistic was the appropriate statistical tool for testing the hypotheses because the data were metric and the two samples were randomly and independently drawn from populations assumed to be normally distributed.

A significance level of 0.05 is used for the t-tests at 97 degrees of freedom (the t-test statistic follows a t-distribution with $50+49-2=97$ degrees of freedom). Since these are two-tailed tests, the significance level has to be divided into two equal parts; upper and lower tails $(0.05 / 2=0.025)$. The critical value on the $t$-distribution table at 0.025 significant level corresponding to 97 degrees of freedom is then compared with the computed or estimated $t$-value. The decision rule is that if $t_{\text {est }}$ (where $t_{\text {est }}=t$-estimated) is greater than $t_{\text {cr }}$ (where $t_{\text {cr }}=t$-critical) then the null hypothesis is rejected in favour of the alternative hypothesis or if $t_{\text {est }}$ is less than $-t_{\mathrm{cr}}$. That is, reject $\mathrm{H}_{0}$ if $\mathrm{t}_{\mathrm{est}}>\mathrm{t}_{\mathrm{cr} 97}$ or if $\mathrm{t}_{\mathrm{est}}<-\mathrm{t}_{\mathrm{cr} 97}$, otherwise do not reject $\mathrm{H}_{0}$. Alternatively, the $\mathrm{p}$-value (probability) usually labelled as "Sig" which stands for "significance" on the output table of the SPSS independent samples test can also be used as the decision criteria to reject or accept the $\mathrm{H}_{0}$. That is, reject $\mathrm{H}_{0}$ if $\mathrm{p}>0.025$ (two-tailed) otherwise do not reject $\mathrm{H}_{0}$. Generally, the t-Test for Differences in two means is given by the following formula:

$$
t=\frac{\mu_{1}-\mu_{2}}{s_{p}^{2} \sqrt{\left(\frac{1}{u_{p}}+\frac{1}{p_{2}}\right)},} \begin{aligned}
& \text { where } \mu_{1}=\text { mean of sample } 1, \mu_{2}=\text { mean of sample } 2 \\
& n_{1}=\text { size of sample } 1, n_{2}=\text { size of sample, } \\
& \\
& S_{p}^{2}=\text { pooled variance defined as follows: }
\end{aligned}
$$




$$
\begin{gathered}
s_{p}^{2}=\frac{\left(n_{1}-1\right) s_{1}^{2}+\left(n_{2}-1\right) s_{2}^{2}}{n_{1}+n_{2}-2}, \text { and } \\
S^{2}=\text { variance of sample } 1 \\
S^{2}{ }_{2}=\text { variance of sample } 2
\end{gathered}
$$

The test statistic t follows a t distribution with $n_{1+} n_{2}-2$ degrees of freedom

The Mann-Whitney/Wilcoxon rank sum test is used to compare the quality of health care received by the insured and uninsured and because the samples are two independent random samples, a two sample test is conducted. The Mann-Whitney/Wilcoxon rank sum test is appropriate for the test because the variable of interest (quality of health care) is ranked in order of magnitude for both the insured and uninsured. The level of significance is 0.05 but this is divided into two equal parts since this is a two-tail test $(0.05 / 2=0.025)$ so 0.025 is the required level of significance. The P-value must be in the range of $(0.000-0.025)$ in order to be considered significant. The Mann-Whitney U-test has three formulae but for this study, one of the formulae is used: the one for larger samples. This formula is chosen because the samples involved are greater than 20; 51 insured households and 49 uninsured households $\left(\mathrm{n}_{1}, \mathrm{n}_{2}>20\right)$. Therefore, the Mann-Whitney U-test is given by the following formula:

$$
\begin{aligned}
& \mathrm{U}_{1}=\mathrm{R}_{1}-\frac{\mathrm{n}_{1}\left(\mathrm{n}_{1}+1\right)}{2} \\
& \mathrm{n}_{1}=\text { sample size for sample } 1, \mathrm{R}_{1}=\text { sum of the ranks in sample } 1 \\
& \mathrm{U}_{2}=\mathrm{R}_{2}-\frac{\mathrm{n}_{2}\left(\mathrm{n}_{2}+1\right)}{2} \text { where } \\
& \mathrm{n}_{2}=\text { sample size for sample } 2, \mathrm{R}_{2}=\text { sum of ranks in sample } 2 \\
& \text { the sum of the equations }(1)+(2) \text { is now computed as follows: }
\end{aligned}
$$

$$
\mathrm{U}_{1+} \mathrm{U}_{2}=\mathrm{R}_{1}-\mathrm{n} 1 \frac{\left(\mathrm{n}_{1}+1\right)}{2}+\frac{\mathrm{R}_{2}-\mathrm{n}_{2}\left(\mathrm{n}_{2}+1\right)}{2}
$$

With regards to the correlation analysis, the Cramer's V correlation coefficient is used to evaluate the relationship between income and insurance status; to establish whether there are any relationship, and if there is indeed a relationship, the strength of this relationship between income and insurance status. The Cramer's V correlation coefficient is the appropriate correlation measure to use because the variable "income" is ranked or ordered (income is in categories, in sequence and coded with ordered numerals showing increasing amounts of wealth) while the variable "insurance status" is a dichotomous variable (you are either insured or not insured). The decision rule is that the coefficient ranges in value from 0.0 to 1.0. The closer a coefficient is to 1.0 , the stronger the association and the closer a coefficient is to 0.0 , the weaker the relationship. Also, the coefficient is either positive or negative-this indicates the direction of the relationship. Generally, the Cramer's V coefficient is given by the following formula:

Cramer's $\mathbf{V}$ coefficient $=\sqrt{ } \mathbf{x}^{2} / \mathbf{N}(\mathbf{k}-\mathbf{1})$ where,

$x^{2}=$ is the computed chi square value

$N=$ Total frequency (sample size)

$k=$ the smaller of $R$ (the number of Rows) or $C$ (the number of columns)

$I=i$ a constant

Finally, data generated from the FGDs were transcribed and categorised in order to bring out essential patterns. The data were analysed qualitatively in the form of narratives based on the evidences.

\section{Results and Discussions}

\subsection{An Overview of the Kassena-Nankana District}

The Kassena-Nankana District (KND) is one of the 9 districts in the Upper East Region of Ghana with Navrongo as its capital. According to the Kassena-Nankana District Assembly (2007), the District lies within the Guinea 
Savannah woodlands with a total land area of about $1,674 \mathrm{sq} . \mathrm{km}$. The population of the District is estimated to be 154,000 as at 2009 and consists of 151 communities - majority of which are rural, only 13 per cent of the population live in towns. They have similar socio-cultural institutions such as the extended family system and patrilineal inheritance. The main economic activity of the District is subsistence agriculture. Agriculture employs over $68 \%$ of the total economically active population and contributes about $60 \%$ to Gross Domestic Product (GDP) (ibid). In terms of health care, malaria is endemic accounting for over $60 \%$ of all outpatients seen at health facilities and $25 \%$ of under-five mortality in the District. Health care in the District is constrained mainly by finance, limited number of health facilities accessible to the population and inadequate health personnel. The District has a Doctor/Patient ratio of 1:75488 and Nurse/Patient ratio of 1:5245 (ibid). The Kassena-Nankana Mutual Health Insurance Scheme (KNMHIS) was launched in 2004 in line with the general policy framework of the National Health Insurance in Ghana to provide financial protection to the people especially the poor. According to official sources from the scheme's secretariat, the scheme has so far registered 79,029 people, representing $57 \%$ of the total population of the district (KNMHIS, 2007).

\subsection{Insurance Premiums and Indigene Policy}

The District MHIS in line with the National Health Insurance Authority has put in place an indigene policy to take care of the poorest of the poor (the indigenes) who have been deemed to be unable to pay the annual insurance premium based on a means test or criteria. According to the staff of the Scheme, a person must meet the following criteria to be classified as an indigene. If the person:

- is unemployed and has no visible source of income

- does not have a fixed place of residence according to standards determined by the scheme

- does not live with a person who is employed and who has a fixed place of residence and

- does not have any identifiable consistent support from another person"

Those who meet the above criteria and pregnant women are exempt from paying the insurance premiums and must only register with the scheme to receive medical attention free of charge. The process of identifying the indigene is often a difficult task. It is often politicised. Staff of the Scheme however, intimated that traditional leaders, assembly members and some community members play a vital role in helping to identify the indigenes in the various communities.

The Scheme charges an annual insurance premium of GHф11.00 per person for informal sector employees between the ages of 18 and 69 years. This category of people must pay GH $\phi 10.50$ to renew their cards annually. A grace period of one month is given to households to renew their cards after one year period. Households who fail to renew their cards after the one month grace period are made to pay a penalty fee of GHф 5.00 on every member of the household in addition to the annual registration fee before it is allowed to register again. This measure was instituted by the scheme to curb drop-outs. Those with Social Security and National Insurance Trust (SSNIT) contributions pay $2.5 \%$ of their contributions as insurance premium directly to the MHIS via the NHIA hence they only need to pay an annual registration of $\mathrm{GH} \phi 3.00$ in order to access health care. The aged, 70 years and above, children less than 18 years, and pensioners pay an annual registration of GHф 3.00 and are thus exempt from insurance premiums. They must also pay GHф 2.50 annually to renew their insurance, failure of which also attracts the penalty.

\subsection{Socio-Economic Characteristics of members and non-members}

The ages of respondents ranged between 18 years and $60+$ years. The age limit of 18 years was chosen because people of this age are considered adults and can therefore be household heads. However, the youngest household head in the survey was 26 years while the oldest household head was 80 years. Both the insured and uninsured households earn low incomes but the insured are generally households that earn higher incomes than the uninsured households. About $53.10 \%$ of the uninsured earn an average income less than GH $\not 10.00$ (US\$6.85) whereas $15.67 \%$ of the insured earn an average income less than GH $\not 10.00$ a month. In Gaani males constituted $74 \%$ of the respondents with $26 \%$ being female. In Pindaa $88 \%$ of the respondents were males while females constituted only $12 \%$. Again in Gaani $72 \%$ of the respondents were married, $6 \%$ were reported divorced while the widowed constituted 22\%. In Pindaa $88 \%$ were married, $4 \%$ were never married, $2 \%$ were divorced and $6 \%$ were widowed. As far as ethnicity is concerned, $94 \%$ of the respondents in Gaani were Nankana with $6 \%$ Kassenas. In the case of Pindaa, $96 \%$ of the respondents were Kassenas while the Nankana formed only $4 \%$. The average household size was 5.41. The minimum household size was 1 while the maximum household size was 11. Malaria constituted $38.38 \%$ of all the illnesses that households suffered from, diarrhoeal related illnesses constituted 19.24\%; injury related illnesses constituted $19.10 \%$ while other illnesses constituted $23.28 \%$ 
respectively. Majority ( $86 \%$ ) of the respondents have never been to school, $9 \%$ have attended primary school, $3 \%$ have attended Junior High School, 1\% has attended Secondary School and also $1 \%$ has attained tertiary education.

\subsection{MHIS and its Impact on Financial Protection}

Access to health care was measured using the frequency of use of health services by the insured and uninsured. The level of financial protection against the financial consequences of illness was also measured using out-patient and in-patient treatment costs for both insured and uninsured.

\subsubsection{Frequency of use of Health Facilities}

The frequency of use of health facilities during the last year 2008-2009 for both the insured and uninsured was generated by means of cross tabulation. The cross tabulation shows that majority $(57.14 \%)$ of uninsured use the health facility once a year while only $9.80 \%$ of the insured use the health facility within the same period. Also, $38.78 \%$ of the uninsured use health facilities between $2-4$ times while $56.91 \%$ of the insured use health facilities between 2-4 times in a year. Similarly, only $4.08 \%$ of the uninsured use health facilities 5 times or more whereas $31.30 \%$ of the insured use health facilities 5 times or more during the same period (See Table 1).

For the data above there are two independent samples involved (one of insured and the other of uninsured people) and so the objective is to find out whether a difference exists between the means of the two samples. For this data, the null and alternative hypotheses are stated as follows:

$\mathrm{H}_{0}: \mu_{1}=\mu_{2}$ (where $\mu_{1}=$ mean frequency of use for the insured and $\mu_{2}=$ mean frequency of use for the uninsured): There is no difference in the means of frequency of use of health facilities between the insured and uninsured.

$\mathrm{H}_{1}: \mu_{1} \neq \mu_{2:}$ There is a difference in the means of frequency of use of health facilities between the insured and uninsured

From the Independent Samples Test, the calculated t-value is 5.041 for equal variances not assumed and the critical t-value corresponding to 0.025 on the t-distribution table at 97 degrees of freedom is 1.9847 and a $\mathrm{p}$-value of (0.000). Since the computed or estimated t-value (5.041) is greater than the critical t-value (1.9847); that is $\left(\mathrm{t}_{\mathrm{est}}=5.041>\mathrm{t}_{\mathrm{cr} 97}=1.9847\right)$, the $\boldsymbol{H}_{0}: \boldsymbol{\mu}_{1}=\boldsymbol{\mu}_{2}$ is rejected in favour of the $\boldsymbol{H}_{1}: \boldsymbol{\mu}_{\boldsymbol{l}} \neq \boldsymbol{\mu}_{2}$. This means that there is statistically significant difference in the frequency of utilisation of health facilities between the insured and uninsured which confirms the research hypothesis. The Mean Difference of 2.283 suggests that the insured use nearly 3 times of health facilities as compared to the uninsured. The high frequency of use of health facilities by the insured could be a possible sign of moral hazard. In fact, interviews with the staff of the KNMHIS indicate that there have been reported cases of client moral where some clients visit multiple health facilities about 4 times in a week. There have also been reported cases of "whole family" visiting the health facility the same day. These evidences are however, anecdotal and need to be further investigated. Besides, the issue of moral hazard is highly contestable for the rural poor who earn their incomes on daily basis; the time spent seeking health care at the health facilities has very high opportunity costs if they are really not sick.

\subsubsection{Costs of treatment}

The cost of treatment includes both out-patient and in-patient costs. The cost of health care incurred by the insured and uninsured is reflected in the monthly expenditure on health. For instance, the findings show that the uninsured generally spend more on health than the insured. It is established that $88.29 \%$ of the insured pay less than GH\& 10.00 (\$6.85) whereas only $14.29 \%$ of the uninsured spend the same amount in a month on health. These amounts include in-patient and out-patient care as well as premium payments (See Table 2).

From Table 2, as the monthly expenditure on health increases, the percentage expenditure on health by the uninsured also increases while that of the insured decreases drastically. What is more striking from the table is that no insured household spends between GHS 40.00 (\$27.40) \& $50.00(\$ 34.25)$ in a month whereas as much as $26.53 \%$ of the uninsured spend this amount in a month. Based on the descriptive statistics above, the aim here is now to use inferential statistics; to do hypotheses testing to find out whether there is a difference in the mean costs of treatment (out-patient and in-patient) between the insured and uninsured. The hypotheses are stated as follows:

$\mathrm{H}_{0}: \mu_{1}=\mu_{2}$ (where $\mu_{1}=$ mean cost for the insured and $\mu_{2}=$ mean cost for the uninsured.): There is no difference in the mean costs of treatment between the insured and uninsured.

$\mathrm{H}_{1}: \mu_{1} \neq \mu_{2}$ : There is a difference in the mean costs of treatment between the insured and uninsured. 
The cost of treatment also involves two independent samples and the variable "cost" is measured in monetary terms and so it is a metric variable. Therefore, the t-test statistic is the appropriate statistical measure to use to test the hypotheses. The results of the t-test show a computed or estimated t-value of (-7.520) and p-value of (0.000). The corresponding lower-tail critical t-value is (1.9847) at 97 degrees of freedom. The estimated t-value $\left(t_{\text {est }}\right)$ is less than the critical t-value ( $\left.\mathrm{t}_{\mathrm{cr}}\right)$ : i.e. $\mathrm{t}_{\mathrm{est}}=-7.520<-\mathrm{t}_{\mathrm{cr} 97}=-1.9847$. Based on these results, the $\mathbf{H}_{\mathbf{0}}: \boldsymbol{\mu}_{\mathbf{1}}=\boldsymbol{\mu}_{2}$ is rejected in favour of the $\mathrm{H}_{1}: \mu_{1} \neq \mu_{2}$. This means that there is a significant difference in the costs of treatment between the insured and uninsured. The mean difference of -2.00 seems to suggest that the costs of treatment for insured appear to be lower than that of the uninsured.

It has also been found that a total of 7 households reported that a member of their households was hospitalised during the period under consideration of which five (5) were insured and two (2) were uninsured household members. The average cost for the five (5) insured persons was GH $\& 4.00$ for five days of hospitalisation whereas the two (2) uninsured persons paid GH $\notin 11.50$ for two days of hospitalisation. This implies the uninsured paid about $\mathrm{GH} \notin 5.75$ a day out-of- pocket while the insured paid less than $\mathrm{GH} \varnothing 1.00$ a day- that is $\mathrm{GH} \phi 0.80$ pesewas a day. Assuming that an uninsured household member is hospitalised for say 11 days, he pays GHф63.25 (GH $\varnothing$ $5.75 \times 11$ ) out-of-pocket for the cost. One interesting finding is that one uninsured household paid as much as GH $\phi 98$ for the cost of surgery during the period under consideration. These costs as compared to those of the insured are relatively large and can push families into poverty in the event that the breadwinner of the family is hospitalised or has to undergo surgery.

In line with the theoretical background, these findings are consistent with earlier findings on the impact of MHI on access to health care that suggested that there is consistent evidence that MHI membership is associated with lower out-of-pocket payments for health care (Ekman, 2004 cited in Chankova, Sulzbach and Diop, 2008). In fact, insured households were further asked to list the four (4) most important reasons why they are enrolled in MHIS. The evidence from their responses shows that majority (60.78\%) are insured because the MHI facilitates access to health care while $21.57 \%$ said they were enrolled because they trusted that the system was good. This evidence from the questionnaire was supported by the FGDs that were held with insured households in both communities. For instance, the groups were asked to compare their status without health insurance against their status with health insurance now to see which one gave them better access to health care. One of the respondents had this to say during one of the focus group discussions:

Now pregnant women don't die at home again. At first when there was no insurance, many women died in labour at home but such cases are now very rare. So the scheme is very good.

Thus both the household survey and FGDs are consistent in highlighting the fact that health insurance facilitates access to health care for the poor and can be considered as a major relief in terms of seeking health care in times of sickness.

\subsection{MHIS and its Impact on Quality of Health Care}

Quality of health care in this context relates to the responsiveness of the health system to the clients and how clients perceive the responsiveness and not the quality of medical treatment per se. Quality of health care was measured using the variables waiting time (how long it takes a sick person to wait to see a health provider), attitudes of health providers towards patients, and the general satisfaction of the respondents about the health services provided.

4.5.1 Waiting Time at the Health facility: The waiting time here deals with the length of time it takes a sick person to see a health provider at the health facility. The household survey shows that $58.33 \%$ of the uninsured receive medical attention or treatment immediately at the health facilities whereas $50.00 \%$ of the insured receive attention immediately. Also, $27.08 \%$ of the uninsured indicate that they wait for less than 30 minutes to see a health provider whereas $42 \%$ of the insured wait for the same time to see a health provider. The detailed information is presented on Table 3 below.

4.5.2 Attitude of Health Providers towards Patients: The attitude of health providers towards patients was measured using the following criteria: very good, good, bad and very bad. The survey revealed that $59.18 \%$ of the uninsured say that the attitude of health providers is very good while that of the insured is $78.00 \%$. Interestingly, neither the insured nor the uninsured found the attitude of health providers to be very bad or bad.

4.5.3 General Satisfaction about Services Received at the Health Facilities: Respondents were also asked to rank their general satisfaction about the services they receive at the health facilities based on the following criteria: very satisfied, somewhat satisfied and not satisfied. The study revealed that $88.00 \%$ of the insured were very satisfied while $85.71 \%$ of the uninsured were very satisfied. On the other hand, $12.00 \%$ of the insured indicated 
that they were somewhat satisfied with $14.29 \%$ of the uninsured being somewhat satisfied. Again, neither the insured nor uninsured indicated that they were not satisfied with services provided at the health facility. There was one non-response as far as the quality of health is concerned- one insured household. The perceptions of the insured and uninsured about the quality of health care have also been summarised as shown on Table 3 below.

The raw data on table 3 does not show any difference in the quality of health care as far as insurance status is concerned. It is thus worthwhile to compare the quality of health care received by the insured and uninsured using quantitative statistical analysis by doing hypotheses testing in order to draw informed conclusions. The hypotheses are the following:

\section{$\mathrm{H}_{0}$ : there is no difference in the quality of health care received by the insured and uninsured.}

$\mathrm{H}_{1}$ : the insured received better quality health care than the uninsured.

The Mann-Whitney U-test/Wilcoxon rank test is appropriate for testing the hypotheses because the variable of interest (quality of health care is rank in order of magnitude and the samples are also independent random samples. The results show a Sig. (2-tailed) P-value of (0.365). This value is greater than $0.025(0.365>0.025)$. Therefore, the alternative or research hypothesis that assumed that the insured receive better quality health care than the uninsured is rejected in favour of the null hypothesis. These results show that there is no statistically significant difference in the quality of health care received by either the insured or the uninsured.

However, analyses of the FGDs in relation to quality of health care show very interesting results: the findings are directly opposed to the findings from the quantitative analysis above. The FGDs show clear differences in the quality of health care received by the insured and uninsured. It is indicated that the uninsured are rather attended to promptly at the health facility, better respected and are generally given quality drugs than the insured. A member of the FGD had this to say:

The MHIS is very good but one thing that we (insured) encounter is that when you have the insurance card and you go to the hospital, you do not receive quick services. The health providers rather treat the uninsured before they attend to us the insured. The health providers get 'something' from the uninsured. With the insured, they know they cannot get anything from you so they will not have that time for you. When you go to the hospital and you don't control your anger, you will surely come home with your sickness untreated. They will shout on you in a way that your own father has never done. They don't regard us the insured at all. ---- Yes, sometime I was sick and went to the hospital. We were in a queue waiting. As we waited the uninsured people just came and they were given immediate consultation, prescription and drugs and we were still sitting. This is because they are going to pay cash. So this is one thing that is bringing back the success of the MHIS.

These findings are very interesting for two reasons. Firstly, it appears that in assessing the quality of health care, qualitative methods might be better than quantitative methods since the qualitative methods allow the respondents to express their views freely thereby eliciting responses that quantitative methods may not. And secondly, the cultural setting of the respondents also seems to play a role. For instance, in the study area, when someone is even very sick and the person is asked; 'how is your health' the person will say 'I am fine'. The person will never say that 'I am not fine'. Thus it is likely that because the questionnaire asked directly about the attitude of health providers and satisfaction about the health services provided, both the insured and uninsured decided to say they were satisfied reflecting the cultural values of the study area. The FGDs further suggest that some health providers (nurses) intentionally inflate the prices of certain drugs for the uninsured for their own advantage hence they tend to give immediate attention to the uninsured. It is also reported that the insured are usually given drugs that cannot even cure headache while the uninsured rather get better drugs. For instance, it was reported during FGDs with the insured that: "now that we are health insured, paracetamol is our only medicine"

\subsection{Socio-Economic Determinants of Membership}

\subsubsection{Household Income}

The interest here is to evaluate the relationship between income and insurance: whether the income level of households is associated with enrolment in health insurance. Using a cross tabulation of average monthly income and insurance status (See Table 4), the household survey revealed that about $53.10 \%$ of the uninsured get an average income of less than GH $\not 10.00(\$ 6.85)$ a month while only $15.67 \%$ of the insured get an average income of less than GHS 10.00 . In the same vein, about $20.41 \%$ of the uninsured get an average income monthly income between GH 10.00 (\$6.85) and GHф 20.00 (\$13.70). Table 4 shows that the insured are generally households that earn higher incomes than the uninsured households. In fact, it is interesting to find out from table 3 that no uninsured household gets an average monthly income between $\mathrm{GH} \phi 60.00$ (\$41.10) and GHф 80.00 (\$54.80). 
Due to the fact that the uninsured are generally the very poor households, they tend not to seek early treatment at the formal health facilities. In fact, majority (93.75\%) of the uninsured treat their illnesses at home and only seek treatment at the formal health facilities when they rate the illness as severe. Only $6.25 \%$ of the uninsured seek medical attention at the formal health facilities when they perceive their illnesses as mild or moderate. However, $74 \%$ of the insured seek health care immediately at the formal health facilities when they consider their illnesses as mild or moderate. In order to uncover whether the two variables (income and insurance status) are related or not a bivariate analysis is done. In this regard, the Cramer's V correlation coefficient is used to examine the relationship between the two variables. The results show a Cramer's V value of 0.41 . The Cramer's V value of 0.41 is also positive and is moderate. Based on these results, it can be concluded that there is a moderately positive relationship between income and insurance status.

\subsubsection{Reasons for not enrolling in Insurance}

Households were further asked to list the reasons for which they are not enrolled in the MHIS. It was established that $61.20 \%$ of households are not enrolled because they could not afford the flat rate premium, $12.50 \%$ said the premium was simply too expensive for them. Importantly, $24.48 \%$ of households indicated that they are not enrolled in the MHIS because there was "No facility nearby". This implies that financial constraints together with the distance to the health facility prevent households from enrolling in MHIS. Indeed, analysis of the data generated by the FGDs also confirms the above trend. For instance, during one of the FGDs one respondent had this to say:

There is nobody who does not want to be enrolled in the MHIS but poverty is making us unable to pay the premium or registration fees. The cost is too high. Over here there is poverty. Some of us want to register but the money is our problem. You know getting food alone is a problem. So just imagine if you have no food and someone comes to tell you to pay this amount to register with health insurance, will that not be a problem? I think if the government can subsidise the insurance premiums or registration fees it will help us the poor to also enrol in the MHIS.

Another interesting finding from the FGDs is that the KNMHIS has introduced a GH $\not 5.00$ penalty fee to encourage households and individuals to renew their insurance promptly. The penalty fee according to the management of the KNMHIS was introduced to control dropout rate from the scheme. The respondents complained that the penalty fee is too high and rather serves to restrict people from joining the health scheme than encouraging prompt renewals of insurance. The following quote attests to this fact:

Another thing is their penalty fee. The charge is too much. They should know that the person has no money that is why he/she is not able to renew his/her insurance card at the specified time. Now if the person struggles to get that money and then they tell him/her to pay a penalty fee of GH\& 5.00 on each household member before the household is allowed to re-register with the scheme, it is not proper. Imagine a household of about 6-10 members, where is the household head getting that GH $\varnothing 5.00$ from? So that is one serious problem.

Similarly, the FGDs revealed that the management of the KNMHIS also introduced GH $\not 1.50$ for the cost of a card holder- a kind of purse in which insured members will keep their insurance identity cards (ID) to protect them from fading and also enable members not to lose their cards. The decision to introduce the purse system according to the respondents was taken without prior consultation with the community members and clients. It was brought to light that even if a household pays all the premiums for all its members without paying the $\mathrm{GH} \phi$ 1.50 for the purse, the IDs will not be handed over to the household. So in the event that a household member falls sick within this period, s/he will not have access to health care despite the fact that $\mathrm{s} / \mathrm{he}$ is insured. A respondent had this to say about the $\mathrm{GH} \phi 1.50$ fees:

How can you suffer to pay for an insurance premium or registration fees and when you are going for your card they ask you to pay an additional GH\& 1.50 before your card is given to you? I paid the insurance premium for 8 of us in my family and now they are telling me to come and pay for these card holder or purse before I can collect the cards. Now how am I going to get GH $\varnothing 1.50$ for each card for 8 cards (GHф 12.00). You can imagine the cost. So I am worried. Are they trying to say that the covers are more important than the cards?

Clearly the GH $\varnothing 1.50$ fee may prevent households from enrolling in the MHIS. It is even more disadvantageous to the uninsured because households or individuals who already could not secure enough money to pay insurance premiums might be restrained perpetually from enrolling in the MHIS because of the additional fee. In this light, one uninsured respondent during FGDs laments that: 
They are punishing we those who are uninsured. That additional money can cause someone's inability to register because you could have the money for the card but not the cover and because of that you don't register with the scheme.

It must also be pointed out that the criteria for a person to meet in order to be classified as an indigene rather tends to exclude majority of the poorest segment of society from accessing health insurance and for that matter health care because experience from the field based on the socio-economic status of the respondents shows that there are several households who genuinely cannot pay the annual insurance premium yet do not qualify as indigenes. For instance, it is possible for an indigene to be living with another person who may be unable to pay his/her own insurance premiums but who has a fixed place of residence.

\section{Conclusions and Policy Recommendations}

The research findings lead to the conclusion that the introduction of mutual health insurance in Ghana has been a very potent strategy for extending social protection in health to the rural poor and vulnerable in society because it improves access to health care for the rural poor. There are significant differences in the costs of treatment and the frequency of use of health facilities between the insured and uninsured. The insured are found to pay relatively lower out-of-pocket fees for the cost of health care than the uninsured. MHI thus offers financial protection to its members; at least from the financial consequences associated with the use of medical care. As a result, the frequency of use of health facilities by the insured is higher than the uninsured; the insured are nearly 3 times more likely to use health facilities than the uninsured. Consequently, majority (93.75\%) of the uninsured postpone sending their illnesses to the health facilities for treatment due to the high cost involved. They (uninsured) manage or treat their sicknesses at home and only seek medical attention at the health facilities when they consider the sickness to be critical and beyond home management. In practice also, the indigene policy does not seem to be improving the poor's access to health care because no household was found to be insured because of its status of being "indigene". The findings also indicate that there is no statistically significant difference in the quality of health care received by the insured and uninsured despite the fact that the FGDs point strongly to the fact that the uninsured are rather more satisfied with the quality of the services they receive. Enrolment in MHI is not automatic for all rural households. The income level of households is the major determinant of enrolment. The insured are generally the rural middle class with relatively higher level of incomes. The poorest of the poor in the rural communities risk being excluded from mutual health insurance because they cannot afford the insurance premiums. Households are generally enrolled in the MHIS because it facilitates access to health care.

Based on the research findings and conclusions above, a number of policy recommendations are made to include majority of the rural poor in MHIS in a bid to improving their access to health care and to ensuring the delivery of quality health care.

6.1 Flexibility in premium payment procedure: Since the flat rate nature of insurance premium is what prevents majority of households from enrolling in health insurance, the premium could be made a little more flexible for the rural poor. For instance, the Management of the Mutual Health Insurance Scheme may accept payments in kind from households. Also, the collection of fees and premium may also be planned to coincide with the harvest period when most of the rural people would have harvested their crops and may be able to pay for insurance at that time. Besides, it is important to revise the indigene criteria because the current one excludes many people. An independent body can be instituted to scout for the indigene in the various communities. Non-Governmental Organisations and other philanthropic organisations could come to the aid of the poorest in society by paying their registration fees and insurance premiums so as to enable them participate in the MHIS.

\section{References}

Bailey, C. (2004). 'Extending social security in Africa'. ESS Paper No. 20, ILO, Geneva.

Bryman, A. (2008). Social Research Methods, Oxford University Press.

Chankova, S., Sulzbach S. and Diop F. (2008). Impact of mutual health organizations: evidence from West Africa. Health Policy and Planning 2008; 23:264-276. Oxford University Press. doi:10.1093/ heapol/czn011

Gottret, Pablo and Schieber, George. (2006). Health Financing Revisited. A Practioner's Guide. 1818 H Street, NW. Washington, DC 20433. The World Bank.

Jütting, Johannes. (2001). 'The impact of health insurance on the access to health care and financial protection in rural areas of developing countries: The example of Senegal'. Centre for Development Research. 53113 Bonn, Germany. 
Jütting, P Johannes. (2005), Health Insurance for the Poor in developing Countries. Croft Road, Aldershot. Hampshire GU113HR, England: Ashgate Publishing Limited, Gower House.

Kassena-Nankana District Assembly. (2007). District Profile. Navrongo, Kassena-Nankana District Assembly

Kassena-Nankana Mutual Health Insurance Scheme. (2007). Annual Report. Navrongo, District Mutual Health Insurance Scheme.

Lasser, U. and Rademacher R. (Eds). (2006). Elements of the Health Care Financing Process. Financing Health Care. A dialogue between South Eastern Europe and Germany. International Public Health. Vol 18. Hellweg 72, 32791 Lage Gerhard Schmal, Düsseldorf. Jacobs-Verlag, pp.9-23

McIntyre, D., Gilson, L. and Mutyambizi,V. (2005). Promoting equitable health care financing in the African context: Current challenges and future Prospects'. Regional Network for Equity in Health in Southern Africa (EQUINET). EQUINET Discussion Paper Number 27. www.equinetafrica.org/bibl/docs/DIS27fin.pdf (Accessed: August 20, 2010)

Preker, A.S. and Carrin, G. (Eds). (2004), Health Financing for Poor People. Resource Mobilization and Risk Sharing. 1818 H Street, NW. Washington, DC 20433. The World Bank. Accessed: July 12, 2010 from: http://www.karmayog.org/communityhealth/upload/2478/HF\%20for\%20Poor\%20-\%20WB,\%20WHO,\%20ILO. pdf

Tabor, S. R. (2005). Community-Based Health Insurance and Social Protection Policy. Social Protection $\begin{array}{llll}\text { Discussion } & \text { Paper } & \text { Series. } & \text { No. }\end{array}$ http://siteresources.worldbank.org/SOCIALPROTECTION/Resources/0503.pdf. The World Bank

United Nations Development Programme. (2007). Human Development Report: Ghana. Towards a More Inclusive Society. UNDP Publications. Combert Impressions.

Waddington C. and Enyimayew K.A. (1989). 'A price to pay: the impact of user charges in Ashanti-Akim district in Ghana'. Part I. International Journal of Health Planning and Management 4: 17-47. doi:10.1002/hpm.4740040104, http://dx.doi.org/10.1002/hpm.4740040104

Wagstaff, A. (2008), 'Measuring Financial Protection in Health', Policy Research Working Paper 4554. The World Bank Development Research Group. 1818 H Street, NW. Washington, DC 20433. World Bank.

World Health Organisation. (2005). National Health Accounts. Geneva, World Health Organisation. http://www.who.int/nha/en/ (August 4, 2010).

Zweifel, Peter. (2007). The Theory of Social Health Insurance. The Netherlands. Now Publishers Inc. 2600 AD Delft

Table 1. Frequency of use of health facilities within the last year (May-June, 2008-2009)

\begin{tabular}{|lllll|}
\hline $\begin{array}{l}\text { Frequency of use of } \\
\text { health facility }\end{array}$ & $\begin{array}{l}\text { Number of } \\
\text { Insured }\end{array}$ & Percentage & $\begin{array}{l}\text { Number of } \\
\text { Uninsured }\end{array}$ & Percentage \\
\hline 0 & 1 & 1.96 & 0 & 0.00 \\
1 & 5 & 9.80 & 28 & 57.14 \\
2 & 13 & 25.50 & 12 & 24.50 \\
3 & 6 & 11.80 & 5 & 10.20 \\
4 & 10 & 19.61 & 2 & 4.08 \\
5 & 5 & 9.80 & 1 & 2.04 \\
6 & 2 & 3.92 & 0 & 0.00 \\
7 & 1 & 1.96 & 0 & 0.00 \\
8 & 4 & 7.84 & 0 & 0.00 \\
9 & 0 & 0.00 & 0 & 0.00 \\
10 & 2 & 3.92 & 1 & 2.04 \\
11 & 1 & 1.96 & 0 & 0.00 \\
12 & 1 & 1.96 & 0 & 0.00 \\
Total & $\mathbf{5 1}$ & $\mathbf{1 0 0}$ & $\mathbf{4 9}$ & $\mathbf{1 0 0}$ \\
\hline
\end{tabular}

Source: Field Survey 2009 
Table 2. Household Monthly Average Expenditure on Health and Insurance Status

\begin{tabular}{|l|l|l|l|l|}
\hline \multirow{2}{*}{ Ave. Monthly Expenditure on Health } & \multicolumn{4}{|c|}{ Insurance Status of Respondents } \\
\cline { 2 - 6 } & \multicolumn{3}{|c|}{ Insured } & \multicolumn{2}{c|}{ Uninsured } \\
\cline { 2 - 6 } & Number & Percentage $(\%)$ & Number & Percentage (\%) \\
\hline Less than GH $\phi \quad 10.00(\$ 6.85)$ & 45 & 88.29 & 7 & 14.29 \\
\hline Between GH $\phi \quad 10.00$ and 20.00 $(\$ 13.70)$ & 5 & 9.80 & 18 & 36.73 \\
\hline Between GH $\phi \quad 20.00 \& 30.00(\$ 20.55)$ & 0 & 0.00 & 5 & 10.20 \\
\hline Between GH $\phi \quad 30.00 \& 40.00(\$ 27.40)$ & 1 & 1.96 & 6 & 12.24 \\
\hline Between GH $40.00 \& 50.00(\$ 34.25)$ & 0 & 0.00 & 13 & 26.53 \\
\hline TOTAL & $\mathbf{5 1}$ & $\mathbf{1 0 0}$ & $\mathbf{4 9}$ & $\mathbf{1 0 0}$ \\
\hline
\end{tabular}

Source: Field Survey, 2009

Table 3. Perceptions of the Insured and Uninsured about the Quality of health Care

\begin{tabular}{l|llll}
\hline \multirow{2}{*}{ Quality of Health Care } & \multicolumn{4}{c}{ Insurance Status } \\
\cline { 2 - 5 } & Insured & \multicolumn{3}{c}{ Uninsured } \\
\hline Attitude of Health Personnel & Very Good & Good & Very Good & Good \\
& $(78.00 \%)$ & $(22.00 \%)$ & $(59.18)$ & $(40.82)$ \\
\multirow{2}{*}{ General Satisfaction } & Very Satisfied & Somewhat Satisfied & Very Satisfied & Somewhat Satisfied \\
& $(88.00)$ & $(12.00)$ & $(85.71)$ & $(14.29)$ \\
\hline
\end{tabular}

Source: Field Survey, 2009

Table 4. Monthly Average Incomes of the Insured and Uninsured

\begin{tabular}{lllll}
\hline \multirow{2}{*}{ Ave. Monthly Income } & \multicolumn{3}{l}{ Insurance Status of Respondents } \\
\cline { 2 - 5 } & Insured & \multicolumn{3}{l}{ Uninsured } \\
\cline { 2 - 5 } & Number & Percentage & Number & Percentage \\
\hline Less than GHS $10.00(\$ 6.85)$ & 8 & 15.67 & 26 & 53.10 \\
\hline Between GHS 10.00 and GHS $20.00(\$ 13.70)$ & 11 & 21.60 & 10 & 20.41 \\
\hline Between GHS $20.00 \& 30.00(\$ 20.55)$ & 9 & 17.65 & 6 & 12.24 \\
\hline Between GHS $30.00 \& 40.00(\$ 27.40)$ & 8 & 15.67 & 3 & 6.12 \\
\hline Between GHS $40.00 \& 50.00(\$ 34.25)$ & 7 & 13.73 & 2 & 4.08 \\
\hline Between GHS 50.00 \& $60.00(\$ 41.10)$ & 5 & 9.80 & 2 & 4.08 \\
\hline Between GHS $60.00 \& 70.00(\$ 47.95)$ & 1 & 1.96 & 0 & 0.00 \\
\hline GHS $80.00(\$ 54.80)$ and above & 2 & 3.92 & 0 & 0.00 \\
\hline TOTAL & $\mathbf{5 1}$ & $\mathbf{1 0 0}$ & $\mathbf{4 9}$ & $\mathbf{1 0 0}$ \\
\hline
\end{tabular}

Source: Field survey, 2009 